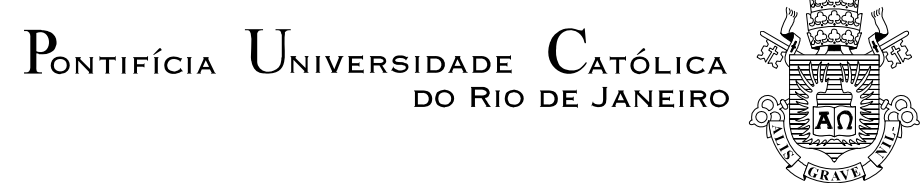

Tamara Wajnberg

Desalinhamento cambial e crescimento econômico

Um estudo sobre a relação entre câmbio, poupança e crescimento

Dissertação de Mestrado

Dissertação apresentada como requisito parcial para obtenção do título de Mestre pelo Programa de Pós-Graduação em Economia da PUC-Rio.

Orientador: Ilan Goldfajn Co-orientador: Samuel de Abreu Pessôa

Rio de Janeiro

Março de 2008 


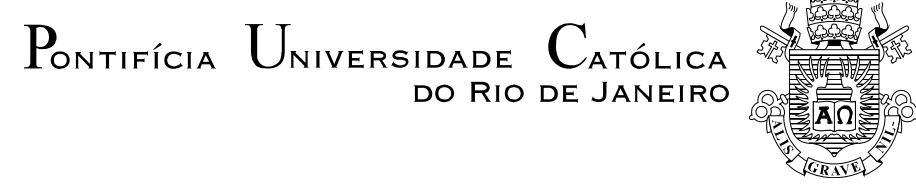

Tamara Wajnberg

\section{Desalinhamento cambial e crescimento econômico \\ Um estudo sobre a relação entre câmbio, poupança e crescimento}

Dissertação apresentada como requisito parcial para obtenção do título de Mestre pelo Programa de PósGraduação em Economia da PUC-Rio. Aprovada pela Comissão Examinadora abaixo assinada.

Prof. Ilan Goldfajn

Orientador

PUC-Rio

Prof. Samuel de Abreu Pessôa

Co-orientador

FGV-Rio

Prof. Márcio Gomes Pinto Garcia

PUC-Rio

Prof. Carlos Eduardo Soares Gonçalves

USP-SP

Prof. Nizar Messari

Coordenador Setorial do Centro de Ciências Sociais - PUC-Rio

Rio de Janeiro, 07 de março de 2008 
Todos os direitos reservados. É proibida a reprodução total ou parcial do trabalho sem autorização da universidade, do autor e do orientador.

\section{Tamara Wajnberg}

Graduou-se em Economia pela PUC-Rio, em 2004, onde também cursou o Mestrado em Economia entre 2006 e 2007.

Ficha Catalográfica

Wajnberg, Tamara

Desalinhamento cambial e crescimento econômico: um estudo sobre a relação entre câmbio, poupança e crescimento / Tamara Wajnberg ; orientador: Ilan Goldfajn; co-orientador: Samuel de Abreu Pessôa 2008

89 f. : il. ; $30 \mathrm{~cm}$

Dissertação (Mestrado em Economia)-Pontifícia Universidade Católica do Rio de Janeiro, Rio de Janeiro, 2008.

Inclui bibliografia

1. Economia - Teses. 2. Crescimento de longo prazo. 3. Taxa de câmbio real. 4. Desalinhamentos cambiais. 5. Poupança. I. Goldfajn, Ilan. II. Pessôa, Samuel de Abreu. III. Pontifícia Universidade Católica do Rio de Janeiro. Departamento de Economia. IV. Título. 


\section{Agradecimentos}

Ao meu orientador, professor Ilan Goldfajn, pela atenção dispensada, discussões estimuladas e sugestões dadas durante todo o período de elaboração desta dissertação. Os anos de convívio me proporcionaram enorme amadurecimento acadêmico, pessoal e profissional.

Ao meu co-orientador Samuel Pessôa, por participar de forma tão efetiva no processo de amadurecimento e compilação das idéias aqui expostas. Suas valiosas sugestões e contribuições foram essenciais para o sucesso deste projeto.

Aos professores Márcio Garcia e Carlos Eduardo Soares, pelos comentários e sugestões feitos durante a defesa desta dissertação, que certamente me ajudaram a refletir sobre questões relevantes para o estudo do tema em questão.

Ao professor Marcelo Medeiros, pelos bons conselhos acerca dos métodos econométricos utilizados neste trabalho.

Aos meus colegas de mestrado da PUC-Rio, em especial André Diniz, Juliana Salomão e Isabela Guarino, tanto pela colaboração nas discussões teóricas e empíricas relativas à esta dissertação, como pela ajuda mútua dispensada durante os dois anos de curso.

A todos do Departamento de Economia da PUC-Rio, por me proporcionarem seis anos de ensino de qualidade superior e altamente profissional, fundamental na minha formação profissional como economista.

Em particular, ao professor Rogério Werneck que, além de dispertar meu 
interesse pela macroeconomia, foi um grande conselheiro durante toda a minha vida acadêmica.

Minha sincera gratidão à minha mãe Maria do Carmo Wajnberg, ao meu pai Mario Wajnberg e ao meu irmão Daniel, pelo apoio moral, afetivo e financeiro durante todo o período do curso (e da vida). Por fim, ao meu namorado Henrique Pereira, agradeço pelo amor, carinho e paciência durante todo o período deste trabalho.

Finalmente, ao governo brasileiro pelo apoio financeiro. 


\section{Resumo}

Wajnberg, Tamara; Goldfajn, Ilan (Orientador); Pessoa, Samuel de Abreu (Co-orientador). Desalinhamento Cambial e Crescimento Econômico: um estudo sobre a relação entre câmbio real, poupança e crescimento. Rio de Janeiro, 2008. 89 p. Dissertação de Mestrado - Departamento de Economia, Pontifícia Universidade Católica do Rio de Janeiro.

O debate em torno da relação entre câmbio real e crescimento, apesar de antigo no meio acadêmico, se fortaleceu com as experiências de alguns países asiáticos de rápido crescimento econômico e manutenção da taxa de câmbio real em níveis muito baixos. Estudos recentes documentam que desvalorizações cambiais até certo nível podem ter efeito positivo sobre o crescimento, enquanto que sobrevalorizações são sempre negativas. O objetivo desta dissertação é mostrar que existe uma relação direta entre poupança doméstica e câmbio real, e entre poupança e crescimento, de forma que os resultados mencionados acima falham ao não levar em consideração a dinâmica conjunta destas três variáveis. Para isso, mostramos, primeiramente, evidência teórica de que países com maiores taxas de poupança, ao mesmo tempo em que apresentam câmbio real mais desvalorizado, também são aqueles que apresentam maiores taxas de crescimento da produtividade. Adicionalmente, realizamos uma análise empírica para 80 países durante o período de 1970 a 2004, onde calculamos o câmbio de equilíbrio incluindo a taxa de poupança como um de seus fundamentos, e em seguida, estimamos a correlação dos desvios do câmbio com relação ao nível de equilíbrio (calculado na etapa anterior) com o crescimento. A análise das regressões mostra que os desvios cambiais, ao levarem em consideração o efeito da poupança sobre o câmbio de equilíbrio, não parecem ser correlacionados com o crescimento econômico. Ao passo que, políticas de estímulo à poupança doméstica, ao mesmo tempo em que influenciam o câmbio de equilíbrio, também parecem promover maior crescimento econômico.

\section{Palavras-chave}

Crescimento de longo prazo; taxa de câmbio real; desalinhamentos cambiais; poupança. 


\section{Abstract}

Wajnberg, Tamara; Goldfajn, Ilan (Advisor); Pessôa, Samuel de Abreu (Co-advisor). Real exchange rate misalignment and Economic Growth: An investigation about the relation between real exchange rates, savings and growth. Rio de Janeiro, 2008. 89 p. MSc Dissertation Economics Department, Pontifícia Universidade Católica do Rio de Janeiro.

The debate about the relation between real exchange rates and economic growth, even though old in the academics circle, grew strongly with the Asian experience of fast economic growth and the maintenance of low levels of real exchange rates. Recently, studies have shown that undervaluation of the real exchange rate until some level could have positive impact on growth, while overvaluations are thought to (always) have negative relation with economic performance. We will argue in this work that these results fail to take into consideration the dynamics of a third variable: the country's savings rate. First we show theoretical evidence that countries with higher savings rate will have a more devalued real exchange rate and at the same time, will show higher productivity growth rates. Secondly, we present an empirical analysis of 80 countries during the period from 1970 to 2004, were we calculate the equilibrium real exchange rate including the savings rate as one of its fundamentals, and after that, we estimate the relation between the real exchange rate deviation from its equilibrium level and economic growth. The regression analysis shows us that the real exchange rate misalignment is not correlated at all with a country's economic performance. We conclude that policies that stimulate the savings decision are much more important for growth than the deviations of the exchange rate that does not reflect the economy's fundamentals.

\section{Keywords}

Long-run economic growth; real exchange rate; real exchange rate misalignments; savings rate. 


\section{Sumário}

1 Introdução 12

$\begin{array}{ll}2 \text { Revisão da Literatura } & 17\end{array}$

2.1. Câmbio Real como Política Econômica Expansionista ou

$\begin{array}{ll}\text { Contracionista? } & 17\end{array}$

2.2. Câmbio Real e a Produtividade no Setor de Tradables 18

2.3. Câmbio Real, Poupança e Investimento. 19

2.4. Câmbio Real e a Alocação Ótima de Capital entre Setores 21

2.5. Desalinhamentos e volatilidade do câmbio afetando

negativamente o crescimento de países 22

3 Modelagem Teórica $\quad 24$

3.1. Relação entre Câmbio Real e Poupança 24

Modelo 25

3.2. Relação entre Poupança e Crescimento 28

4 Metodologia e Fonte de Dados 34

4.1. Sobre a relação entre câmbio real e seus fundamentos 34

4.1.1. Definições 34

4.1.2. Estimação do câmbio de equilíbrio 38

4.1.3. Fonte de Dados $\quad 41$

4.2. Sobre a relação entre câmbio real e crescimento 43

4.2.1. Questões econométricas sobre a relação entre câmbio real e crescimento 43

$\begin{array}{lr}\text { 4.2.2. Fonte de Dados } & 47\end{array}$

5 Experiência Internacional: Análise Empírica 49

5.1. Análise da estimação do câmbio real de equilíbrio 49

5.2. Análise da Regressão de crescimento 51 
5.3. Robustez

5.3.1. Comparação com o estudo de Aguirre e Calderón (2005)

5.3.2. Analisando a heterogeneidade da amostra

6 Conclusão

58

7 Referências Bibliográficas

61

8 Apêndice 66

8.1. Tabelas e Figuras 66

8.2. Modelo de Crescimento e Poupança de Aghion, Comin e Howitt (2006).

8.3 Lista de países utilizados nos exercícios $\quad 77$

8.4 GMM em diferenças e Sistema GMM 87 


\section{Lista de figuras}

Figura 1: Correlação entre poupança e crescimento.

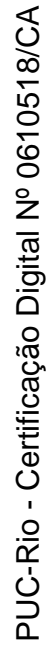




\section{Lista de tabelas}

Tabela 1: Crescimento e preço de consumo por região ............................66

Tabela 2: Crescimento, preço do consumo e poupança por região ..........66

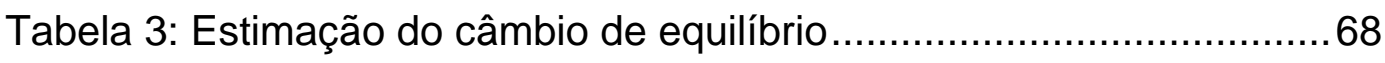

Tabela 4: Estatísticas descritivas do desalinhamento cambial..................69

Tabela 5: Estatísticas descritivas dos determinantes do crescimento

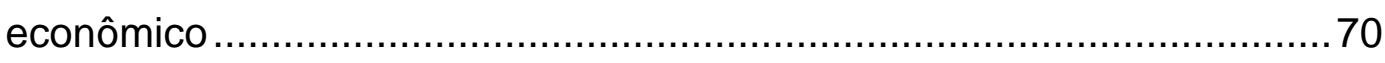

Tabela 6: Correlações bivariadas.......................................................... 70

Tabela 7: Crescimento econômico e desalinhamento cambial...................71

Tabela 8: Crescimento econômico, desvalorizações e

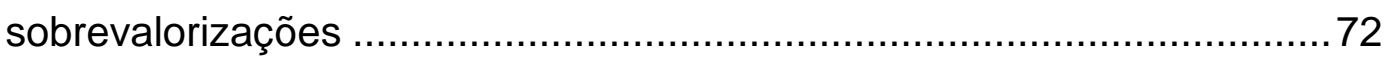

Tabela 9: Crescimento, gastos do governo e poupança .......................... 73

Tabela 10: Robustez - Comparação com AC ..........................................74

Tabela 11: Robustez - Heterogeneidade da amostra (I) ..........................75

Tabela 12: Robustez - Heterogeneidade da amostra (II) .........................76 